\title{
浅析房产测量对不动产登记的影响及其措施
}

\author{
陈鹏飞 ${ }^{1} \quad$ 邵俊轩 ${ }^{2}$ \\ 1 浙江省国土勘测规划有限公司杭州分公司 2 浙江省测绘科学技术研究院 \\ DOI:10.32629/gmsm.v3i4.770
}

\begin{abstract}
[摘 要] 我国房地产发展逐渐壮大,不动产登记业务管理也日趋完善。在整个登记办理环节中,房产测量 发挥着非常高效的作用与价值,对于房产市场的约束,房产信息的提供都有着积极的促进作用。有效保障 房产测量工作的质量, 不仅对于维护正常的房地产市场秩序有着十分重要的作用, 而且能够有效避免纠 纷的发生, 这对于房地产行业的长远与可持续发展至关重要。基于此, 本文分析了房产测量对不动产登记 的影响及其措施。
\end{abstract}

[关键词] 房产测量; 不动产登记; 影响; 措施 中图分类号: O353.5 文献标识码: A

\section{1 不动产登记中房产测量的主 要内容}

房产测量属于不动产测量工作的重 要组成部分, 房产测量作为最基础的测 量服务工作, 在整个不动产的测量工作 中发挥着非常重要的作用。随着社会经 济的高速发展, 人们生活质量水平的不 断提高, 房产测量工作也发生了相应的 转变。房产测量工作已经从传统的地籍 测量, 转变为专业的测量学科, 能够采用 先进的科学信息技术, 准确高效的仪器 设备, 来对房屋的面积、位置、权属、质 量、数量、使用现状等各种信息展开全 面详细的了解, 然后将其制作成相应的 文字、图表、数据等, 直观形象的呈现在
人们面前, 来帮助人们更好的了解最终 的测量结果, 为相关部门提供准确可行 的决策依据。

\section{2 房产测量所产生的深远影响}

2. 1 提供方便便利的登记

以往的进行不动产登记的时候, 同 时需要消耗大量的人力物力等资源, 以 及对时间的一种消耗。此外工作的实施 进展相对缓慢, 产生严重的低效率工作, 相关的信息还完成不了及时的更新。在 不断的发展进化的过程当中, 测量工作 中, 其他相关部门就进行有效的融合, 极 大地提高不动产的登记管理工作, 对于 整体登记工作的效率也具有显著的促进 作用, 更好的避免了相关错误的出现, 从
而能够为人们提供优质化的服务。

2. 2 确保房产所有人的自身利益

房产登记中利用到房产测量还能 够有效的保障房产所有人的自身权益。 在将房产进行登记之前, 进行房产测量 工作可以较好的明确产权所有人的权 利以及义务。同时负责房产登记的工作 人员要对相关不动产的知识做好充分 的储备, 房屋权利人也要保障好自身的 房产权益, 保护自身权益不受侵犯和威 胁。当遇到房产问题纠纷时, 房产测量 能够根据所得出的测量成保障好房产 所有人的权益。

2.3 能够提升信息的透明性

近年来国家各级政府部门均开始进
些远程测量, 对外部环境的要求并没有 严格的规定。

由此可见, 不同的技术也有着一定 的区别, 那么在实际应用中, 就需要技 术人员结合相应的需求, 对测绘方案进 行优化和和调整, 从而进一步保证测绘 效果。

\section{4 总结}

综上所述, 无人机技术、信息技术、 集成技术等技术在测绘工程中有着十分 广泛的应用。虽然目前测绘工程设备小 型化是主要的发展方向, 但是进一步提 升设备的测绘精度仍然是测绘人员重点
关注的问题。并且, 在实际测量过程中往 往需要应对丰富复杂的测绘环境, 因此 测绘设备复杂环境的应对能力也将成为 未来测绘技术主要的发展方向。想要真 正提出有效的技术方案, 就需要技术人 员不断提升自身业务水平, 对技术进行 更为深入的研究和分析, 明确不同技术 的优势和特点, 提出行之有效的技术优 化方案。

\section{[参考文献]}

[1]张瑞.测绘工程技术在地籍 测量中的实践应用分析 [J]. 科技 风,2020,(10):111.
[2]徐小芳, 田剑,徐勇.测绘工程技 术在不动产测量中的实践应用分析 [J]. 工程技术研究,2020,5(03):39-40.

[3] 吴泽强. 无人机遥感技术在测绘 工程测量的应用分析 [J]. 智能城 市,2020,6(02):52-53.

[4] 陈浩, 苏文强.测绘新技术在 测绘工程测量中的应用分析 [J]. 智能城 市,2020,6(08):79-80.

[5]郭强.浅析测绘工程测量技术 的发展与应用分析 [J]. 世界有色金 属,2019,(22):196+199. 
行不动产登记信息的透明化处理, 在此 情况下, 房地产的测量工作备受重视。 主要因为相关的测量工作, 有助于实现 登记在册的相关不动产信息全面审核 目的, 这样在一定程度上可以确保不动 产信息的真实性和合理性, 准确的对其 进行评估处理, 并达到快速识别的目 的。与此同时, 在信息透明化的情况下, 还能正确将违法犯罪行为识别出来, 维 护人们的合法权益, 并全面提升政府部 门的公信力, 将相关的信息透明化的积 极作用与优势等充分发挥出来, 达到预 期的工作目标。

\section{3 不动产统一登记后的测量工 作优化措施}

3.1完善不动产登记测量的标准

目前, 在不动产测量方面的标准大 都参考的事2000国家大地坐标, 但是也 有一些房产部门沿用的是1985国家大地 坐标, 还有一些使用的是城市独立坐标, 这样三者之间的数据衔接和标准就存在 很大的问题, 比如一个不动产可能就会 出现不同的高程值和坐标值, 这也导致 数据无法在平台上实现共享。还有就是 测量数据方面也有不统一的问题, 比如 不动产的面积、地理位置等由于无法关
联为后期整合工作带来了麻烦与困难。 因此, 制定完善且科学统一的法律法规, 让此项工作有章可循、执行顺畅、标准 统一是需要完善与改进的方向。

3.2 建立健全不动产登记的法律 法规

不动产法律法规和相关条例有很 多, 不同法规和条例之间存在着一定的 矛盾性和重复现象, 这对不动产的房产 测量工作带来很多问题和困难, 不利于 相关部门和工作人员更好地开展工作。 因此, 各地区的住房部门和工作人员、 人大代表、政协代表等应该向国家、政 府等建言献策, 建议完善与健全不动产 登记制度, 完善相应的配套法律法规与 相关政策条例, 规范不动产登记模式等, 进而让相关法律法规和政策条例更好 地发挥作用, 服务于房产测量和不动产 统一登记。

3. 3 研发和应用工程房产测量新 技术

随着科学技术的不断发展与成熟, 为房产测量工作也带来技术上的支持, 不仅能够确保房产测量的准确性, 而且 能够有效提升房产测量的效率。同时, 还应该加大在房产测量技术上的人力、
物力以及财力投入, 积极引进先进的技 术人才, 推动房产测量技术的不断发展 与创新。只有不断加强工程勘察技术, 才能从根本上解决目前房产测量技术中 存在的问题, 从而更好地提高施工房产 测量技术的准确性。

\section{4 结语}

总之, 房产的测量技术成果的准确 性可直接对购房者的经济利益造成很大 的影响。虽然我国现在的测量技术也逐 渐的走向成熟, 但是在实际的房产测量 中因为多方面原因的影响还存在不少问 题, 这切身这关系着老百姓的根本利益。 所以, 测量单位应该运用一些高新技术 和方法来提高测量结果的精确度, 以保 证国家和人民利益。从而为建筑行业的 健康发展做出积极的贡献。

\section{[参考文献]}

[1]司峰,毛国栋.浅议房产测量 在房产管理中的作用 [J]. 科学与财 富,2018,(33):280.

[2]王晓光.浅议房产测量在房产管理中 的作用[J].建材与装饰,2018,(28):213-214.

[3]高阳,徐靖轩.浅议房产测量在房 产管理中的作用[J].建筑工程技术与设 计,2018,(29):3291. 